\title{
Praktische Hinweise
}

Zugrundegelegt ist dem Kommentar die 1995 erschienene Teubneriana Konrad MÜLLERs (nach ihr sind in der Regel auch die Fragmente Petrons zitiert). Den einleuchtenden Hinweis einer Besprechung aufgreifend, geben in diesem Band die Lemmata stets den meines Erachtens richtigen Text an, und nicht (wie durchgängig in Band eins) den Text MÜLLERs auch in den Fällen, in denen im Lemma für eine andere Lesart plädiert wurde. Im Kommentar nicht nachgewiesene Konjekturen finden sich in den Ausgaben BüCHELERs bzw. MülLERs (am ehesten in BüCHELERs und MÜLLERs edd. mai.).

Römische und griechische Autoren sind im allgemeinen nach OLD und LSJ zitiert. Um Missverständnisse zu vermeiden, aber auch bei selteneren Namen, erscheinen gelegentlich ausführlichere Abbreviaturen. Die passim verwendeten Kürzel TH und BC stehen für die Troiae Halosis (Sat. 89) bzw. das Bellum civile (Sat.119-124).

Abweichungen von MüLlERs Teubneriana

\begin{tabular}{|c|c|c|}
\hline & Teubneriana & Kommentar \\
\hline 112,6 & $\begin{array}{l}\text { conditorium }\langle\text { commune }> \\
\text { familiari ac viro faceret }\end{array}$ & $\begin{array}{l}\text { conditorium familiari ac viro } \\
\text { sacraret (VANNINI) }\end{array}$ \\
\hline 114,3 & † Siciliam modo ventus dabat $\dagger$ & (ohne cruces) \\
\hline 114,4 & itaque hercules & itaque † hercules \\
\hline 114,11 & $\begin{array}{l}\text { si voluerit 〈 mare > } \\
\text { misericors eqs. }\end{array}$ & si voluerit misericors eqs. \\
\hline 115,12 & percussi (...) manibus pectus & percussi (...) manu pectus \\
\hline 115,19 & $\begin{array}{l}\text { ne quid de nobis relinquat } \\
\text { sepultura? }\end{array}$ & ne quid e nobis relinquat sepultura? \\
\hline 117,10 & $\begin{array}{l}\text { tabulasque testamenti omnibus } \\
\langle\text { mensibus }\rangle \text { renovet }\end{array}$ & $\begin{array}{l}\text { t. t. omnibus <occasionibus> renovet } \\
\text { (HABERMEHL) }\end{array}$ \\
\hline 117,12 & , quid vos' inquit eqs. & , quid? vos' inquit eqs. \\
\hline 118,1 & Heliconem & Helicona \\
\hline 118,6 & $\begin{array}{l}\text { fabulosum } \dagger \text { sententiarum } \\
\text { tormentum } \uparrow\end{array}$ & (ohne cruces) \\
\hline
\end{tabular}

Siehe auch S. (615-) $618 \mathrm{zu}$ 114,3 Siciliam modo ventus dabat, S. $631 \mathrm{zu}$ 114,7 〈exanimatam >, S. $721 \mathrm{f}$ zu 116,8 id est soli fortissimi eqs., und S. 798-800 zu 118,6 fabulosum sententiarum tormentum. 